Journal of Animal and Veterinary Advances 9 (1): 118-122, 2010

ISSN: $1680-5593$

(C) Medwell Journals, 2010

\title{
Body Mass Index and Different Body Measurements of Turkish Angora and Van Cats in Two Different Locations
}

\author{
${ }^{1}$ Serkan Erat and ${ }^{2}$ Sevket Arikan \\ ${ }^{1}$ Department of Animal Breeding, ${ }^{2}$ Department of Physiology, \\ Faculty of Veterinary Medicine, Kirikkale University, Kampus, 71451, Yahsihan, Kirikkale, Turkey
}

\begin{abstract}
The aims of the present study were to compare the body mass index and some other body measurements of the Turkish Angora $(\mathrm{n}=20)$ and $\operatorname{Van}(\mathrm{n}=16)$ cats in two different locations (Ankara Zoo $=$ $\mathrm{AOC}$ and the Faculty of Veterinary Medicine, Kirikkale University $=\mathrm{KKU}$ ) and also to determine the prevalence of overweight or obesity in this feline population. The effects of gender, age, location and eye colors were also investigated on the traits measured. The age of the cats ranged from 1-8 years old. Analyzed traits included Body Mass Index (BMI), live Body Weight (BW), Wither Height (WH), Body Length (BL), Head Circumference (HC), Body Condition Score (BCS). None of the cats in this study were found overweight or obese. The BMI of Turkish Van cats was greater than the BMI of Turkish Angora cats. The BW of Turkish Van cats tended to heavier than the Turkish Angora cats but the difference was not significant. The WH, BL and the HC values for both cats were similar. The BCS of Turkish Van cats was significantly greater than the BCS of Turkish Angora cats in KKU. Significant phenotypic correlations were found between the BW and the $\mathrm{WH}$ and the BL and the $\mathrm{HC}$ and the $\mathrm{BMI}$ and the $\mathrm{BCS}$; between the $\mathrm{WH}$ and the $\mathrm{BL}$ and the $\mathrm{HC}$; between the $\mathrm{BL}$ and the $\mathrm{HC}$ and the BCS; between the $\mathrm{HC}$ and the BCS; between the BMI and the BCS. The present study more clearly defines some body traits of the Turkish cats and may help to understand these invaluable cats better.
\end{abstract}

$\underline{\text { Key words: } \text { Cat breed, turkish angora, turkish van, body mass index, body measurements, body condition score }}$

\section{INTRODUCTION}

The Turkish Angora and Van cats are the native cat breeds of Turkey. The Turkish Angora cat was developed on the plains close to Ankara, from which the name of the cat was derived (Arikan et al., 2003). The Turkish Van cat, known as only a voluntarily swimming domestic cat, was originated in Van region of eastern Turkey and has lived there for thousands of years (Helgren, 2000). The colored eyes (any variety of blue, gold or odd-eyed) and mostly white coat color make both Turkish cats unique and valuable. On the other hand, there are conflicting reports on the origin of these Turkish cats (Gure, 1993; Odabasioglu and Ates, 2000; Arikan et al., 2003) and this might be due to the phenotypic similarity among these cats. The numbers of both Turkish cats are in decline and it is hard to find pure Turkish cats in a large numbers. Therefore, researches on the Turkish cats are limited and further quantitative and molecular studies should be done on these cats so that they can be known better.

Two common problems in households cats are excess weight and obesity since feline obesity increases the risk of some diseases such as diabetes mellitus, nonparasitic skin diseases and lameness (Donoghue and Scarlett, 1998). Knowledge of obesity and overweight as a risk factor for disease can raise awareness and target health check up for cats (Lund et al., 2005). The estimation of body composition in pet animals is important for the control of obesity. The Body Mass Index (BMI), which is based upon measurements of body weight and height, is a simple and reliable indicator of obesity and widely used in humans (Ishioka et al., 2007). But there are also researches that used the BMI for the determination of body composition in cats (Miller et al., 1998; Ferguson et al., 2007). The Body Condition Score (BCS), which indicate the amount of fat cover over cats' ribs and abdominal contour, is commonly used to evaluate nutritional condition of the cat, but it is based on subjective estimation (Laflamme, 1997).

The major objectives, therefore, in this study were to compare the BMI and some body measurements of the Turkish Angora and Van cats in two different locations and also to determine the prevalence of overweight or obesity in this cat population. The gender, age, location and eye color effects were also investigated on the body traits of these pedigreed Turkish cats.

Corresponding Author: Serkan Erat, Department of Animal Breeding, Faculty of Veterinary Medicine, Kirikkale University, Kampus, 71451, Yahsihan, Kirikkale, Turkey 


\section{MATERIALS AND METHODS}

Source of data: The total number of cat used in this study was from the Ankara Zoo $(n=20)(A O C)$ and the Faculty of Veterinary Medicine, Kirikkale University $(n=16)$ (KKU) in Turkey. The data consisted of 20 Turkish Angora and 16 Turkish Van cats. Of the cats 25 were females and 22 were odd-eyed. All cats were solid white in color and sexually intact and their ages ranged from $1-8$ years.

Management: The cats in $\mathrm{AOC}$ were housed in adjacent 10 rooms each with at least two but at most four cats. Each room had an outdoor place. The size of each indoor room and outdoor places was approximately 6.25 and $8 \mathrm{~m}^{2}$, respectively. The cats had free run of indoor and outdoor places. The cats in KKU were housed in an indoor room of approximately $5 \mathrm{~m}^{2}$. The male cats were separated from the females which had free run of indoor place. The locations were approximately $70 \mathrm{~km}$ apart on the East-West direction. Feeding of the cats in AOC was twice a day (morning and evening) and the diet consisted of mostly liver, fish, dry food and cooked meat. The cats in KKU had ad libitum access to only commercial dry cat food (Whiskas, Mars, Inc., VA, USA). All cats had access to fresh drinking water at all times and were exposed to natural daylight and temperature in both locations.

Measurements: Live Body Weight (BW), Wither Height (WH), Body Length (BL) and Head Circumference (HC) were recorded. The BW was measured in all cats using a scale with a precision of $5 \mathrm{~g}$. The $\mathrm{WH}, \mathrm{BL}$ and $\mathrm{HC}$ were taken with a cloth tape measure. The WH was measured as distance from the floor beneath the cat to the top of withers directly above the center of shoulder. The BL was measured as distance from the point of the shoulder to the ischiatic tuberosity. The cloth tape measure was wrapped around the circumference of the cat's head just behind the ears and across the forehead for measuring the HC. The $\mathrm{WH}, \mathrm{BL}$ and $\mathrm{HC}$ were recorded in centimeters. All measurements were taken from the left side of the cats. The BMI was determined by dividing the BW $(\mathrm{kg})$ of the cat by the product of the WH and BL $\left(\mathrm{m}^{2}\right)$ (Miller et al., 1998). The BCS was given to cats only in KKU. The Purina body condition score (Laflamme, 1997) was used as a subjective assessment of body condition. The BCS was given on a nine point scale, which ranged from 1 for being emaciated to 9 for being grossly obese. A cat with a BCS score of 5 was considered to be ideal.

Statistical analysis: The data were analyzed using generalized least squares. Analyzed traits included the $\mathrm{BMI}, \mathrm{BW}, \mathrm{WH}, \mathrm{BL}, \mathrm{HC}$ and the BCS. Terms included in the statistical models were cat breed, location, gender, age of the cat and eye status of the cat based on eye color. Cat ages were divided into three groups, group I-III. Group I included ages 1 and 2 years, group II included ages 3 and 5 years and group III included ages from $5-8$ years since there were few cats with the age of 7 and 8 years. For the BCS analysis, cat ages were divided into only two groups, group I and II. Group I included ages 1 and 2, while group II had cats with older than 2 years of age. Eye status of cats defined as odd-eyed if one eye was blue and the other one was yellow or amber and non-odd-eyed if both eyes were the same color. All effects in the model were considered fixed.

Two-way interactions were generally not significant and were not included in the model except that cat breed and location interaction was considered and included in the model. Phenotypic correlations were also calculated between the traits measured. Statistical analyses were performed using GLM and CORR procedures of the SAS (SAS Inst. Inc., Cary, NC, USA).

\section{RESULTS AND DISCUSSION}

Least squares means and standard errors for the BMI, BW, WH, BL and the HC are shown in Table 1.

There was a significant breed effect $(p<0.01)$ on the BMI. The Turkish Van cats had higher BMI than the Turkish Angora cats. The male cats had also higher ( $<<0.05)$ BMI than the female cats. The BMI tended to increase, while the cat aged but this was not significant $(p>0.05)$. Even though no significant $(p>0.05)$ location and interaction effects were observed, the cats in AOC had higher BMI than the cats in KKU. There was also no significant eye status effect for the BMI $(p>0.05)$.

The breed, location, age and eye status effects along with the breed $\mathrm{x}$ location interaction were not significant for the BW $(\mathrm{p}>0.05)$. The male cats were approximately $20 \%$ heavier than the female cats $(\mathrm{p}<0.01)$. There was no noticeable influence of the main effects and the breed $\mathrm{x}$ location interaction for the WH $(\mathrm{p}>0.05)$, but the breed and gender effects approached a significance level $(\mathrm{p}=0.06)$, where the Angora cats were taller than the Van cats and the male cats were taller than the female cats.

All main effects and the interaction term were not significant for the $\mathrm{BL}$ and $\mathrm{HC}(\mathrm{p}>0.05)$.

Least squares means and standard errors for the BCS are shown in Table 2. There was a significant difference $(p<0.01)$ between the cat breeds. The Turkish Van cats had significantly higher BCS than the Turkish Angora cats. The gender, age and eye status effects were not significant for the BCS ( $>>0.05$ ). Based on the cats' BMI and BCS in one location, the Turkish cats in this study were found to be not overweight or obese. 
Table 1: Least squares means and standard errors for Body Mass Index (BMI), live Body Weight (BW), Wither Height (WH), Body Length (BL) and Head

\begin{tabular}{|c|c|c|c|c|c|c|}
\hline Effects & $\mathrm{N}$ & BMI $\left(\mathrm{kg} \mathrm{m}^{-2}\right)$ & BW (kg) & WH $(\mathrm{cm})$ & $\mathrm{BL}(\mathrm{cm})$ & $\mathrm{HC}(\mathrm{cm})$ \\
\hline Breed & & $* *$ & & & & \\
\hline Turkish Angora & 20 & $33.06 \pm 1.26$ & $3.45 \pm 0.17$ & $27.61 \pm 0.52$ & $37.11 \pm 0.83$ & $26.31 \pm 0.54$ \\
\hline Turkish Van & 16 & $38.63 \pm 1.26$ & $3.82 \pm 0.17$ & $26.25 \pm 0.51$ & $37.31 \pm 0.83$ & $25.86 \pm 0.54$ \\
\hline Gender & & $*$ & **** & & & \\
\hline Female & 25 & $33.93 \pm 1.04$ & $3.25 \pm 0.14$ & $26.23 \pm 0.43$ & $36.50 \pm 0.68$ & $25.49 \pm 0.45$ \\
\hline Male & 11 & $37.77 \pm 1.45$ & $4.02 \pm 0.20$ & $27.62 \pm 0.59$ & $37.92 \pm 0.95$ & $26.67 \pm 0.62$ \\
\hline \multicolumn{7}{|l|}{ Location } \\
\hline $\mathrm{AOC}$ & 20 & $37.78 \pm 1.25$ & $3.85 \pm 0.17$ & $27.42 \pm 0.51$ & $37.33 \pm 0.82$ & $26.22 \pm 0.54$ \\
\hline KKU & 16 & $33.92 \pm 1.43$ & $3.42 \pm 0.20$ & $26.43 \pm 0.58$ & $37.09 \pm 0.94$ & $25.95 \pm 0.61$ \\
\hline \multicolumn{7}{|l|}{ Age } \\
\hline Group I & 13 & $33.86 \pm 1.43$ & $3.23 \pm 0.20$ & $26.60 \pm 0.59$ & $35.37 \pm 0.94$ & $25.05 \pm 0.61$ \\
\hline Group II & 14 & $36.28 \pm 1.44$ & $3.74 \pm 0.20$ & $27.19 \pm 0.59$ & $37.69 \pm 0.94$ & $26.54 \pm 0.62$ \\
\hline Group III & 9 & $38.40 \pm 1.70$ & $3.94 \pm 0.23$ & $26.99 \pm 0.70$ & $38.56 \pm 1.12$ & $26.65 \pm 0.73$ \\
\hline \multicolumn{7}{|l|}{ Eye status } \\
\hline Odd eye & 22 & $35.67 \pm 1.37$ & $3.63 \pm 0.19$ & $26.98 \pm 0.56$ & $37.29 \pm 0.90$ & $26.07 \pm 0.59$ \\
\hline No odd eye & 14 & $36.02 \pm 1.18$ & $3.65 \pm 0.16$ & $26.87 \pm 0.48$ & $37.12 \pm 0.77$ & $26.09 \pm 0.50$ \\
\hline \multicolumn{7}{|c|}{ Breed $x$ Location } \\
\hline Angora $\times$ AOC & 14 & $34.41 \pm 1.39$ & $3.77 \pm 0.19$ & $28.53 \pm 0.57$ & $38.31 \pm 0.91$ & $26.66 \pm 0.59$ \\
\hline Angora x KKU & 6 & $31.72 \pm 2.15$ & $3.14 \pm 0.30$ & $26.68 \pm 0.88$ & $34.91 \pm 1.41$ & $25.96 \pm 0.92$ \\
\hline $\operatorname{Van} \times \mathrm{AOC}$ & 6 & $41.14 \pm 1.99$ & $3.94 \pm 0.27$ & $26.31 \pm 0.82$ & $36.34 \pm 1.31$ & $25.77 \pm 0.85$ \\
\hline Van $x \mathrm{KKU}$ & 10 & $36.13 \pm 1.72$ & $3.70 \pm 0.24$ & $26.17 \pm 0.70$ & $38.27 \pm 1.13$ & $25.93 \pm 0.74$ \\
\hline
\end{tabular}

${ }^{*} \mathrm{p}<0.05,{ }^{* *} \mathrm{p}<0.01 ; \mathrm{AOC}=$ Ankara Zoo, KKU $=$ Kirikkale University, Faculty of Veterinary Medicine

Table 2: Least squares mean and standard error for Body Condition Score

\begin{tabular}{lcc}
\multicolumn{3}{c}{$(\mathrm{BCS})^{\dagger}$ of the Turkish Angora and Van cats } \\
\hline Effects & $\mathrm{N}$ & $\mathrm{BCS}$ \\
\hline Breed & & $* * *$ \\
Turkish Angora & 6 & $3.38 \pm 0.23$ \\
Turkish Van & 10 & $4.24 \pm 0.19$ \\
Gender & & \\
Female & 10 & $3.72 \pm 0.17$ \\
Male & 6 & $3.90 \pm 0.23$ \\
Age & 9 & $3.75 \pm 0.16$ \\
Group I & 7 & $3.87 \pm 0.26$ \\
Group II & & \\
Eye status & 3 & $3.73 \pm 0.29$ \\
Odd eye & 13 & $3.89 \pm 0.14$ \\
No odd eye & & \\
***p $<0.01 ; ~ \dagger B C S$ was given only in the Faculty of Veterinary Medicine, \\
Kirikkale University
\end{tabular}

Phenotypic correlations between the body traits of Turkish Angora and Van cats are shown in Table 3. There were moderate to strong correlations $(\mathrm{p}<0.01)$ between the $\mathrm{BW}$ and the $\mathrm{WH}, \mathrm{BL}, \mathrm{HC}, \mathrm{BMI}$ and the $\mathrm{BCS}$. The $\mathrm{WH}$ was moderately correlated $(\mathrm{p}<0.001)$ with the $\mathrm{BL}$ and the $\mathrm{HC}$. The moderate correlations $(\mathrm{p}<0.01)$ were observed between the $\mathrm{BL}$ and the $\mathrm{HC}$ and the $\mathrm{BCS}$. The $\mathrm{HC}$ was moderately correlated $(\mathrm{p}<0.05)$ with the BCS and a strong correlation $(p<0.001)$ was observed between the BMI and the BCS.

In the Turkish Standards Institute publications for Angora and Van cats (Anonymous, 1997a, b) body weights ranged from 2.5-4.0 kg for the Turkish Angora cats older than 8 months and from $2.0-4.5 \mathrm{~kg}$ for the mature Turkish Van cats. Other reported body weights for the Turkish Van cats ranged from $2.8-3.6 \mathrm{~kg}$ (Senler, 1986; Demirulus, 2005; Agaoglu and Yuksek, 2005). All these weights included both genders. In the present study mean body weights of the Turkish Van and Angora cats were 3.82 and $3.45 \mathrm{~kg}$, respectively. Body
Table 3: Phenotypic correlations between the body traits of Turkish Angora

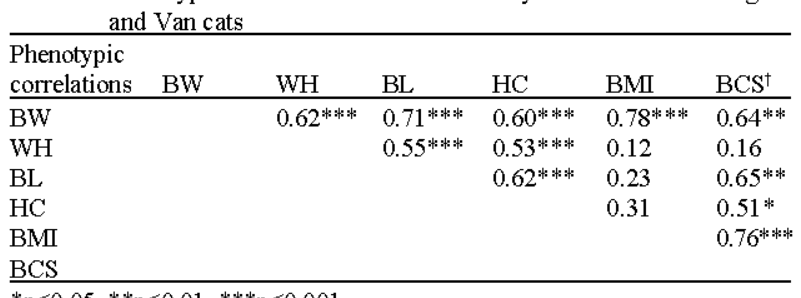
${ }^{*} \mathrm{p}<0.05, * * \mathrm{p}<0.01, * * * \mathrm{p}<0.001$

weights of both breeds were statistically similar ( $p>0.05$ ) in the study and consistent with the weights reported above. The weights of these cats reported so far including the ones in the present study were recorded in Turkey. But outside Turkey, Helgren (2000) reported that the adult Turkish Van cats' body weights for both genders ranged from $4.1-7.7 \mathrm{~kg}$, which is quite heavier than the ones reported in Turkey. Body weights of cats in researches conducted for different breeds of cats vary greatly. In the study by Michel et al. (2005), neutered short-haired male cats ranging in age from 3-4 years had body weight of $7.2 \mathrm{~kg}$ and another neutered short-haired male cats of approximately 1 year of age had body weight of $5.1 \mathrm{~kg}$.

Fettman et al. (1997) investigated the effects of neutering on body weight, metabolic rate and glucose tolerance of domestic short-haired cats ranging in age from 18-24 months. In this study mean body weights for intact males, neutered males, intact females and spayed females were $5.2,4.6,2.9$ and $2.6 \mathrm{~kg}$ before neutering and $5.8,6.0,3.4$ and $3.6 \mathrm{~kg} 3$ months after neutering, respectively. Another study by Fettman et al. (1998) consisting of neutered adult domestic short-haired cats ranging in age from 24-30 months reported a mean body weight of $5.6 \mathrm{~kg}$ for the male and $3.6 \mathrm{~kg}$ for the female cats before weight gain and $6.6 \mathrm{~kg}$ for the male and $4.3 \mathrm{~kg}$ for 
the female cats 3 months after weight gain. All these researches had neutered cats and indicate that neutered male and female cats gain significantly more weight. Hendriks' et al. (1997) research involving intact cats reported a mean body weights of 4.4 and $3.2 \mathrm{~kg}$ for the male and female cats, respectively. Franca and Godinho's (2003) research reported a mean body weight of $3.1 \mathrm{~kg}$ on sexually mature domestic male cats.

There has been little research reported on other body measurements of cats such as wither height, body length and head circumference. The present study reports the body length of the Turkish Van and Angora cats as 37.31 and $37.11 \mathrm{~cm}$, respectively. This measurement for the Turkish Van cats is in agreement with the body length of $30-40 \mathrm{~cm}$ of the adult Turkish Van cats reported (Odabasioglu and Ates, 2000; Demirulus, 2005). The study by Allan et al. (2000) reported the median body length of the cats in their study as $37 \mathrm{~cm}$, which is also consistent with the body lengths reported in the present study.

Although, not statistically significant, all values of body measurement except the WH for the age group II and III were greater and this suggests that the cats in the age group I might be still considered young and might not have reached full maturity yet. It should also be kept in mind that the cats in the present study were all sexually intact. These could partly be the reasons for why the cats in the present study were generally but not always lighter than those reported so far.

The estimation of body composition in any animal species is important for the understanding of subjects such as the control of obesity. Maintaining the ideal body composition for cats, therefore, is necessary since obesity increases the risk of diabetes mellitus, joint problems, skin diseases, hepatic lipidosis and reduced life expectancy Costa (2007). Ferguson et al. (2007) found that obesity significantly increased the BMI of lean female neutered cats from $44.3-54.7 \mathrm{~kg}^{-1} \mathrm{~m}^{2}$. In the study by Miller et al. (1998), cats were grouped according to the BMI. The obese cat group had BMI> $>42 \mathrm{~kg}^{-1} \mathrm{~m}^{2}$, whereas the lean cat group had $\mathrm{BMI}<42 \mathrm{~kg}^{-1} \mathrm{~m}^{2}$. Appleton et al. (2000) reported a mean BMI of cats as 60.8 and $76.5 \mathrm{~kg}^{-1} \mathrm{~m}^{2}$ before and after weight gain, respectively. The BMIs of both Turkish cat breeds in this study fall between 30 and $40 \mathrm{~kg}^{-1} \mathrm{~m}^{2}$ indicating that the Turkish cats are leaner than those cats. But the cats in those studies (Miller et al., 1998; Appleton et al., 2000; Ferguson et al., 2007) were all neutered that could cause a weight increase. The Turkish cats in this study at one location seem to have less than the ideal BCS that is 5. The feeding regimen, motility and castration or spaying can affect the body condition of cats (Donoghue and Scarlett, 1998). The study by Lund et al. (2005) reported that the neutered males had the highest prevalence of overweight (33.3\%) and obesity $(7.7 \%)$, whereas intact females had the lowest prevalence of overweight $(20.4 \%)$ and obesity $(4.8 \%)$. The same study also reports that between the ages 5 and 11 years, over $40 \%$ of all cats were overweight or obese. Even though not statistically significant and all the cats were sexually intact, the male cats had greater BCS than the female cats and the cats in the age group II had also greater BCS than the cats in the age group I in this study indicating tha the results are partly in agreement with the study above (Lund et al., 2005). It was found that overweight and obese cats were more likely to be domestic short, medium and long-haired, mixed or Manx breeds, neutered, male, middle-aged, living in an apartment, not hunting, consuming a premium or therapeutic food and to be simultaneously diagnosed with diabetes mellitus, disease of the oral cavity or urinary tract, neoplasia, or dermatopathy (Donogh and Scarlett, 1998; Lund et al., 2005). In the present study no significant health problems of the cats were reported by the veterinarian at $\mathrm{AOC}$ and clinicians at KKU. This might be due to the fact that none of the cats in this study were overweight or obese and this might affect the health status of the cats.

\section{CONCLUSION}

The results of the present study more clearly define some body characteristics of the Turkish Angora and Van cats. It can also be said that the feeding regimen and housing conditions of the Turkish cats at two different locations in this study seem to be adequate enough since no cats were overweight or obese and had significant health problems. Further studies, especially, molecular ones, need to be done in order to understand both Turkish cat breeds better. Crossbreeding of these cats with each other or with another cat breed are being practiced by some people without knowing that the crossbreeding causes these cats to be mixed and makes it hard to distinguish, which breed is Angora and Van. Therefore, crossbreeding of these cats should be avoided. This concern even grows bigger when it is known that the numbers of both breeds are in decline. The genetic conservation of the Turkish cats, therefore, is very important. The strict pure breeding within these cat breeds should be practiced along with a good selection program so that the number of the pure Turkish cats increases. 


\section{ACKNOWLEDGEMENTS}

The researchers would like to thank Nadir Sahin, Manager of Ankara Zoo, for allowing them to research in Ankara Zoo.

\section{REFERENCES}

Agaoglu, Z.T. and N. Yuksek, 2005. Van kedileri koruma altinda (Van cats are under protection). Infovet, 19: 70-72.

Allan, F.J., D.U. Pfeiffer, B.R. Jones, D.H.B. Esslemont and M.S. Wiseman, 2000. A cross-sectional study of risk factors for obesity in cats in New Zealand. Prev. Vet. Med., 46: 183-196. DOI: 10.1016/S0167-5877(00) 00147-1.

Anonymous, 1997a. Turk Standardi. (Turkish Standard). Dam izl ik hayvanlar-Ankara kedisi (Breeding stocksAngora cat). Turk Standartlar i Enstitusu, TS:12137.

Anonymous, 1997b. Turk Standardi (Turkish Standard). Dam izl ik hayvanlar-Van kedisi (Breeding stocks-Van cat), Turk Standartlari Enstitusu, TS:12138.

Appleton, D.J., J.S. Rand and G.D. Sunvold, 2000. Plasma leptin concentration in cats: Reference range, effect of weight gain and relationship with adiposity as measured by dual energy x-ray absorptiometry. J. Feline Med. Surg., 2: 191-199. PMID: 11716618.

Arikan, S., S.Y. Duru, M. Gurkan, Z.T. Agaoglu and U. Giger, 2003. Blood type A and B frequencies in Turkish Van and Angora cats in Turkey. J. Vet. Med. A Physiol. Pathol. Clin. Med., 50: 303-306. PMID: 12887623.

Costa, C.B.D.A. and A. Alves, 2007. Feline obesity: A review. Clin. Vet., 12 (68): 42-50.

Demirulus, H., 2005. Van kedisi (Van cat). Ekoloji mag., 8: 68-69. http:/www.ekolojimagazin.com/?s= magazin \&id $=33$.

Donoghue, S. and J.M. Scarlett, 1998. Diet and feline obesity. J. Nutr., 128: 2776S-2778S. http://jn.nutrition. org $/ \mathrm{cgi} /$ reprint/128/12/2776S.

Ferguson, D.C., Z. Caffall and M. Hoenig, 2007. Obesity increases free thyroxine proportionally to nonesterified fatty acid concentrations in adult neutered female cats. J. Endocrinol., 194: 267-273. DOI: $10.1677 / \mathrm{JOE}-07-0064$.

Fettman, M.J., C.A. Stanton, L.L. Banks, D.E. Johnson, D.W. Hamar, R.L. Hegstad and S. Johnston, 1998. Effects of weight gain and loss on metabolic rate, glucose tolerance and serum lipids in domestic cats. Res. Vet. Sci., 64:11-16. DOI: 10.1016/S0034-5288(98) 90108-4.
Fettman, M.J., C.A. Stanton, L.L. Banks, D.W. Hamar, D.E. Johnson, R.L. Hegstad and S. Johnston, 1997. Effects of neutering on body weight, metabolic rate and glucose tolerance of domestic cats. Res. Vet. Sci., 62: 131-136. DOI: 10.1016/S0034-5288(97)90134-X.

Franca, L.R. and C.L. Godinho, 2003. Testis morphometry, seminiferous epithelium cycle length and daily sperm production in domestic cats (Felis catus). Biol. Reprod., 68: 1554-1561. DOI: 10. 1095/biolreprod. 102.010652 .

Gure, A., 1993. Van Kedisi (Van cat). In: Abdulkadiroglu, A. (Ed.). Van Kutugu, Yuzuncu Y il Universitesi, Van. Turkey, 8: 722-726.

Helgren, J.A., 2000. The Turkish Van the remarkable swimming cat. Cats, pp: 42-45.

Hendriks, W.H., M.F. Tarttelin and P.J. Moughan, 1997. Seasonal hair growth in the adult domestic cat (Felis catus). Comp. Biochem. Physiol., 116A(1): 29-35. DOI: 10.1016/S0300-9629(96)00113-2.

Ishioka, K., H. Hosoya, H. Kitagawa, H. Shibata, T. Honjoh, K. Kimura and M. Saito, 2007. Plasma leptin concentration in dogs: Effect of body condition score, age, gender and breeds. Res. Vet. Sci., 82: 11-15. DOI: 10.1016/j.rvsc.2006.06.002.

Laflamme, D., 1997. Development and validation of a body condition score system for cats: A clinical tool. Feline Practice, 25 (5-6): 13-18.

Lund, E.M., P.J. Armstrong, C.A. Kirk and J.S. Klausner, 2005. Prevalence and risk factors for obesity in adult cats from private US veterinary practices. Int. J. Applied Res. Vet. Med., 3 (2): 88-96. http://jarvm. com/articles/Vol3Iss2/LUND.pdf.

Michel, K.E., A. Bader, F.S. Shofer, C. Barbera, D.A. Oakley and U. Giger, 2005. Impact of timelimited feeding and dietary carbohydrate content on weight loss in group-housed cats. J. Feline Med. Surg., 7: 349-355. DOI: 10.1016/j.jfms.2005.05.003.

Miller, C., J. Bartges, L. Cornelius, N. Norton and M. Barton, 1998. Tumor necrosis factor-a levels in adipose tissue of lean and obese cats. J. Nutr., 128: 2751S-2752S. http://jn.nutrition.org/cgi/reprint/ $128 / 12 / 2751 \mathrm{~S}$.

Odabasioglu, F. and C.T. Ates, 2000. Van Kedisi (Van cat), Selcuk Universitesi Bas imevi (Selcuk University Press), Konya, Turkey.

Senler, N.G., 1986. Van kedisi'nin biyoloji ve davran is ozellikleri (Biology and behavioral characteristics of Van cat). Yuksek lisans tezi (Master thesis). Yuzuncu Yil Universitesi Fen Bilimleri Enstitusu., Van, Turkey. 